\title{
A Prospective Open-Label Trial of Lamotrigine Monotherapy in Children and Adolescents with Bipolar Disorder
}

\author{
Joseph Biederman, ${ }^{1,2}$ Gagan Joshi, ${ }^{1,2}$ Eric Mick, ${ }^{1,2}$ Robert Doyle, ${ }^{1,2}$ Anna Georgiopoulos, , ${ }^{1,2}$ \\ Paul Hammerness, ${ }^{1,2}$ Meghan Kotarski, ${ }^{1}$ Courtney Williams ${ }^{1}$ \& Janet Wozniak ${ }^{1,2}$ \\ 1 Clinical and Research Program in Pediatric Psychopharmacology, Massachusetts General Hospital, Boston, MA, USA \\ 2 The Department of Psychiatry, Harvard Medical School, Cambridge, MA, USA
}

\author{
Keywords \\ Bipolar disorder; Children; Lamotrigine.

\section{Correspondence} \\ Joseph Biederman, M.D., 55 Fruit Street, \\ YAW 6A, Boston, MA 02114, USA. \\ Tel.: +1-617-726-1743; \\ Fax: +1-617-724-3742; \\ E-mail: jbierderman@partners.org
}

doi: 10.1111/j.1755-5949.2009.00121.x

\begin{abstract}
Aim: To evaluate the safety and efficacy of lamotrigine monotherapy as an acute treatment of bipolar mood elevation in children with bipolar spectrum disorders. Method: This was a 12-week, open-label, prospective trial of lamotrigine monotherapy to assess the effectiveness and tolerability of this compound in treating pediatric bipolar disorder. Assessments included the Young Mania Rating Scale (YMRS), Clinical Global Impressions-Improvement scale (CGI-I), Children's Depression Rating Scale (CDRS), and Brief Psychiatric Rating Scale (BPRS). Adverse events were assessed through spontaneous self-reports, vital signs weight monitoring, and laboratory analysis. Results: Thirty-nine children with bipolar disorder (YMRS at entry: $31.6 \pm 5.5$ ) were enrolled in the study and 22 (56\%) completed the 12-week trial. Lamotrigine was slowly titrated to an average endpoint dose of $160.7 \pm 128.3$ in subjects $<12$ years of age $(\mathrm{N}=22)$ and $219.1 \pm 172.2 \mathrm{mg} /$ day in children $12-17$ years of age $(\mathrm{N}=17)$. Treatment with lamotrigine was associated with statistically significant levels of improvement in mean YMRS scores $(-14.9 \pm$ 9.7, $P<0.001)$ at endpoint. Lamotrigine treatment also resulted in significant improvement in the severity of depressive, attention-deficit/hyperactivity disorder (ADHD), and psychotic symptoms. Lamotrigine was generally well tolerated with marginal increase in body weight $(47.0 \pm 18.0 \mathrm{~kg}$ vs. $47.2 \pm$ $17.9 \mathrm{~kg}, P=0.6$ ) and was not associated with abnormal changes in laboratory parameters. Several participants were discontinued due to skin rash; in all cases, the rash resolved shortly after discontinuation of treatment. No patient developed Steven Johnson syndrome. Conclusions: Open-label lamotrigine treatment appears to be beneficial in the treatment of bipolar disorder and associated conditions in children. Future placebo-controlled, double-blind studies are warranted to confirm these findings.
\end{abstract}

\section{Introduction}

Despite ongoing controversy, pediatric bipolar disorder has gained acceptance in the clinical and research community as a valid clinical entity [1]. It is thought to affect at least $1 \%$ of children and adolescents and is associated with high levels of morbidity and dysfunction $[2,3]$. Presentation of bipolar disorder in youth is predominantly characterized by mixed states with chronicity, complex cycling, and extremely poor functioning [4]. Al- though early treatment of pediatric bipolar disorder could provide an enormous benefit to children, families, and society by alleviating the consequences associated with this chronic psychopathological state, not much is known about its treatment. As a consequence, these children are frequently treated with a multitude of medications with unclear efficacy and inadequate safety data [5].

Although in recent years, the atypical antipsychotics (risperidone, olanzapine, aripiprazole, and quetiapine) have been increasingly used in the treatment of adults 
and youth with bipolar disorder [6-12], these treatments have also been associated with substantial adverse effects especially weight gain, prolactinemia, glycemic dyscontrol, and dyslipidemia. This state of affairs calls for the further evaluation of additional safe and effective treatments for pediatric bipolar disorder.

Lamotrigine is a new generation antiepileptic drug, approved by the FDA in 2003 for the maintenance treatment of adults with bipolar I disorder to delay the time to occurrence of mood episodes (depression, mania, hypomania, and mixed episodes) in patients treated for acute mood episodes with standard therapy. Recent studies have shown that lamotrigine maintenance treatment was more robust in bipolar depression among adults and that adults with rapid cycling respond to lamotrigine [13-18]. Lamotrigine monotherapy (50-200 mg daily) was also reported to be superior to placebo in the treatment of nonrapid cycling bipolar I depression in adults and uncontrolled observations have suggested possible antimanic $[19,20]$, antidepressant [21], and anticycling/mood stabilization properties [13,19,22].

Although not adequately studied in pediatric bipolar disorder, the pharmacokinetics of lamotrigine in children and adolescents have been well studied via its antiepileptic indication. More is known about its safety and tolerability profile in the pediatric population than for many psychotropics currently used in standard clinical practice for the treatment of pediatric mood disorders.

Although serious dermatological reaction including Steven Johnson syndrome has been associated with lamotrigine treatment, clinician awareness, close scrutiny of subjects, and a slow titration rate have reduced the risk of serious rashes [23]. However, lamotrigine has a low liability for metabolic syndrome and weight gain, which could offer the possibility of a better adverse effect profile than other mood stabilizing agents in which weight gain has been a problematic adverse event.

The main goal of this open label pilot study was to begin to address the safety, tolerability, and effectiveness of lamotrigine in the treatment of pediatric bipolar disorder. To this end, we conducted an exploratory, 12week, open-label treatment, pilot study, of youth ages 6-17, who met the DSM-IV diagnostic criteria for bipolar I, bipolar II, or bipolar spectrum disorder. The study results will be used to generate hypotheses for a larger randomized controlled clinical trial. Based on the available literature in adults with bipolar disorder, we hypothesized that lamotrigine will be efficacious and well tolerated in youth with pediatric bipolar and bipolar spectrum disorders. To the best of our knowledge, this is the first study evaluating the antimanic effects of lamotrigine monotherapy in pediatric bipolar disorder.

\section{Methods}

\section{Subjects}

This study was approved by the Human Research Committee at Massachusetts General Hospital and all subjects and parents/guardians provided written informed consent and assent after the study procedures and possible side effects were fully explained. Subjects were outpatients of both sexes, 6-17 years of age, with a diagnosis of bipolar I disorder, bipolar II disorder, or BPD not otherwise specified (NOS) with current manic, hypomanic, or mixed symptoms.

All diagnoses were established by clinical interview of the children and their parents or guardian by an expert clinician supported by structured diagnostic interviewthe Schedule for Affective Disorders and Schizophrenia for School-Age Children-Epidemiologic version [24]- administered to the parent of the child. A diagnosis of bipolar I disorder was based on the DSM-IV diagnostic criteria that require subjects to meet criterion $\mathrm{A}$, an extreme and persistently elevated, expansive, or irritable mood for a period lasting at least 1 week, plus criterion B, manifested by three (four if the mood is irritable only) of seven symptoms during the period of mood disturbance. BP II disorder was defined according to the DSM-IV as hypomania (an abnormal mood lasting at least 4 days), and BPD-NOS was defined as a severe manic mood disturbance that did not meet either time criteria (at least 4 days) or had fewer elements in criterion B (only required two items for elation and three for irritability).

Eligible children were required to have a YMRS [25-28] total score of $\geq 20$ at baseline to enroll in the treatment trial. Rating scales were completed by board certified or board eligible child and adolescent psychiatrists who trained to a high level of interrater reliability in weekly rater meetings. The intraclass correlation score for interrater reliability on the YMRS was 0.81 .

We excluded subjects with any serious, unstable medical illness including hepatic, renal, gastroenterologic, respiratory, cardiovascular, endocrinologic, neurologic, immunologic, or hematologic disease. Subjects with DSM-IV substance (except nicotine or caffeine) dependence within past 3 months or who were judged to be at serious suicidal risk were also excluded from participation. Subjects with a history of sensitivity to lamotrigine, severe allergies, multiple adverse drug reactions, previous bone marrow depression, or serious rashes were also excluded from the study. No patient was entered into the study if they were adequately stabilized on an antimanic therapy. Mood stabilizers, anticonvulsants, antipsychotics, or any other neuroleptic therapy, were not allowed during this study. Antidepressants were also exclusionary to participation. 


\section{Administration of Study Medication}

Subjects were seen at weekly intervals during which measures of safety and effectiveness were assessed by study clinicians. Study medication was counted by the study clinician at every visit in order to be able to determine compliance. Dose was adjusted upward at weekly interval only if (1) response was insufficient (CGIImprovement $>3$ ) and (2) current dose was well tolerated. Side effects and measures of effectiveness were used to guide dosing throughout the study and medication dose could be lowered at any visit, per clinician decision. For children $<12$ years of age, the starting dose was $0.35 \mathrm{mg} / \mathrm{kg} /$ day in two divided doses, rounded down to the nearest $5 \mathrm{mg}$ for week 1 and 2; for weeks 3 and 4 , the dose could be increased if tolerated, to $0.7 \mathrm{mg} / \mathrm{kg} / \mathrm{day}$ in two divided doses, rounded down to the nearest $5 \mathrm{mg}$; for weeks 5 and 6 the dose could be increased by $0.7 \mathrm{mg} / \mathrm{kg} /$ day, every week in two divided doses, rounded down to the nearest $5 \mathrm{mg}$; for weeks $7-11$ the dose could be increased by $1.0 \mathrm{mg} / \mathrm{kg} /$ day, every week in two divided doses, rounded down to the nearest $5 \mathrm{mg}$; depending on response and tolerability- not to exceed the maintenance dose recommended of $5-15 \mathrm{mg} / \mathrm{kg} / \mathrm{day}$ (maximum of $400 \mathrm{mg} /$ day in two divided doses). For adolescents ( $\geqq 12$ years of age), the starting dose was $25 \mathrm{mg} /$ day for week 1 and 2; for weeks 3 and 4, the dose could be increased, if tolerated, to $50 \mathrm{mg} /$ day in two divided doses; in subsequent weeks, the dose could then be increased by $50 \mathrm{mg} /$ week, depending on response and tolerability, not to exceed the usual maintenance dose of 300-500 mg/day in two divided doses.

\section{Administration of Concomitant Medications}

Given the strong overlap of juvenile bipolar disorder with attention deficit hyperactivity disorder (ADHD), stimulant (methylphenidate hydrochloride, dextroamphetamine sulfate, mixed amphetamine salts) and nonstimulant (atomoxetine) medications were allowed during the study if, in the clinician's judgment, it was in the best interest of the patient to continue this treatment or if the patient did not wish to stop stimulant treatment and only if the patient had been on a stable dose for at least 30 days. Four subjects enrolled in the study were receiving concomitant stimulant therapy and two subjects were receiving atomoxetine. Additional concomitant medications allowed according to protocol and employed during the study were lorazepam $(\mathrm{N}=2)$; two subjects received clonidine. Nonpharmacological treatments such as individual, family, or group therapy were allowed if they were in place before the subject joined the study and if the therapy regimen remained the same throughout the study.

\section{Clinician Rated Assessment Scales}

Severity of symptoms of mania was assessed weekly with the YMRS as described above. Depression and psychotic symptoms were assessed at baseline, midpoint and endpoint with the Children's Depression Rating Scale [29] and Brief Psychiatric Rating Scale [30] respectively. To assess clinically significant severity and improvement relative to baseline, we used the NIMH Clinical Global Impression (CGI) severity (CGI-S), and improvement (CGI-I) scales [31]. CGI severity and improvement were assessed separately for depression, mania, conduct disorder, and ADHD. The score for the CGI-S ranges from 1 (normal, not at all ill) to 7 (among the most extremely ill patients). The score for the CGI-I ranges from 1 (very much improved) to 7 (very much worse).

\section{Safety Assessment}

Safety was assessed at each visit using spontaneous reports of treatment-emergent adverse events, changes in vital signs and laboratory measures. Blood pressure and weight were recorded at each visit. Electrocardiogram (ECG), electrolytes, liver function tests, glucose levels, and complete blood count with differential were obtained at baseline and post-treatment.

\section{Definition of Clinical Response}

Response was defined by having either a 30\% reduction in symptoms according to the YMRS at endpoint or by having been judged as "much improved" or "very much improved" on the CGI-Improvement for mania $(\leq 2)$. To reflect the degree of symptom resolution, we also define euthymia as having a YMRS score of $<12$ at study endpoint for symptoms of mania and a CDRS score of $\leq 28$ for symptoms of depression.

\section{Statistical Analysis}

Analyses were intention to treat (ITT). A mixed-effects model repeated measures approach was used to account for missing data in our longitudinal assessments of safety (i.e., weight and vital signs) and efficacy. Statistical significance was determined at $P<0.05$.

\section{Results}

All inclusion and exclusion criteria were assessed by clinical evaluation and all subjects had YMRS scores greater than 20. Fifty-one subjects were consented and assessed for eligibility for the study with 39 subjects being exposed to study medication $(\mathrm{N}=7 \mathrm{did}$ not meet entrance criteria 
and $\mathrm{N}=5$ withdrew consent). The 39 children enrolled in the study were $10.8 \pm 2.9$ years of age and predominantly male $(61 \%, \mathrm{~N}=24)$. Thirty-five $(90 \%)$ of subjects met criteria for bipolar I disorder, one $(2 \%)$ met criteria for bipolar II disorder, and three $(8 \%)$ met criteria for BP-NOS. At study entry, the mean YMRS score was $31.6 \pm 5.5$. Of the 39 subjects enrolled, 22 (56\%) completed the 12-week course; dropouts were due to adverse effects $(\mathrm{N}=10)$, lack of efficacy $(\mathrm{N}=2)$, noncompliance $(\mathrm{N}=2)$, withdrawal of consent $(\mathrm{N}=1)$, or difficulties in meeting the study schedule $(\mathrm{N}=2)$. At study endpoint, the mean dose of lamotrigine was $160.7 \pm 128.3$ in subjects $<12$ years of age $(\mathrm{N}=22)$ and $219.1 \pm 172.2 \mathrm{mg} /$ day in children 12-17 years of age $(\mathrm{N}=17)$.

Figure 1 shows the adjusted weekly YMRS score. Mixed regression analysis demonstrated a statistically significant improvement from baseline within 1 week of treatment with further significant improvement over the next 12 weeks course (Figure 1). At endpoint, in LOCF analyses, the average reduction in YMRS score as $-14.9 \pm 9.7$ points. Lamotrigine was also associated with a statistically significant improvement in symptoms of psychosis (BPRS: $41.0 \pm 7.9$ vs. $29.9 \pm 9.2, P<0.0001$ ), depression (CDRS: $40.1 \pm 12.9$ vs. $31.8 \pm 13.7, P=$ 0.0002 ), and ADHD (ADHD-RS: $35.6 \pm 11.2$ vs. $22.5 \pm$ 15.7, $P<0.0001)$ from baseline to endpoint.
As shown in Figure 2, at study endpoint, 66\% ( $\mathrm{N}=26)$ of subjects had a 30\% reduction in baseline YMRS scores and $54 \%(\mathrm{~N}=21)$ had a $50 \%$ reduction in baseline YMRS scores. $61 \%$ of subjects $(\mathrm{N}=16)$ were rated on CGI-I as "much improved" or "very much improved" at study endpoint on the symptoms of mania and depression improved in $46 \%(\mathrm{~N}=16)$ of subjects. Thus, $66 \%(\mathrm{~N}=26)$ met our a priori criteria of response for acute mania; the CGI-I $\leq 2$ or a $30 \%$ reduction in YMRS score. Using more stringent criteria to define remission we found that $43 \%$ of subjects $(\mathrm{N}=17)$ had CDRS scores $<28$ and $36 \%(\mathrm{~N}=$ $14)$ of subjects had YMRS scores $<12$; and $26 \%(\mathrm{~N}=10)$ were considered euthymic (YMRS $<12$ and CDRS <28) at endpoint (Figure 2).

Metabolic parameters are presented in Table 1. With the exception of a small increase in posttreatment platelet count, plasma sodium, and plasma creatinine levels and a small decrease in QTc, there were no other abnormal laboratory or cardiovascular changes associated with treatment. There was no statistically significant or clinically significant increase in weight from baseline to endpoint $(47.0 \pm 18.0 \mathrm{~kg}$ vs. $47.2 \pm 17.9 \mathrm{~kg}, P=0.6)$. The most commonly reported adverse effects were gastrointestinal (GI) complaints, headache, cold symptoms, and dermatological effects (Fig. 3). Side effects reported as present at the last visit for subjects dropping due to adverse effects

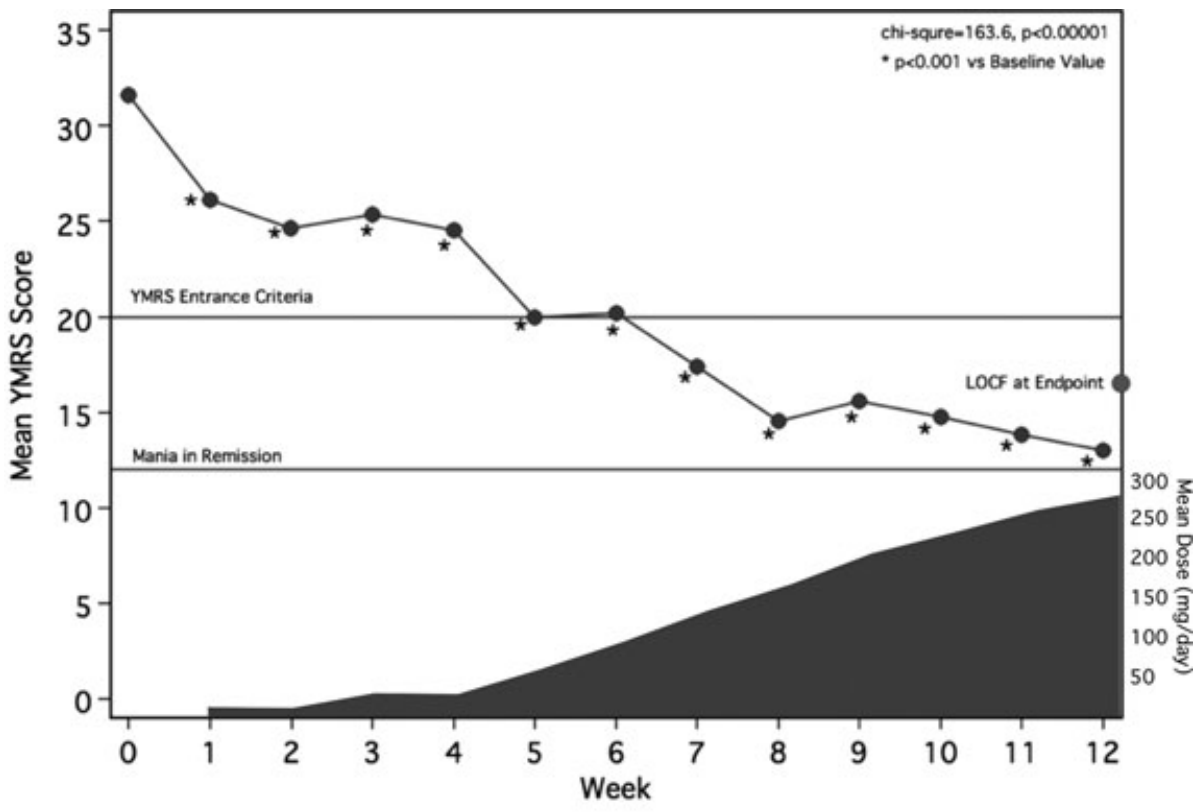

Subjects were required to have a mean YMRS score of $>20$ at baseline to be enrolled. Remission from mania was defined as mean YMRS $<12$.

Figure 1 YMRS Scores in 39 subjects openly treated with lamotrigine over 12 weeks. Subjects were required to have a mean YMRS score of >20 at baseline to be enrolled. Remission from mania was defined as mean YMRS $<12$. 


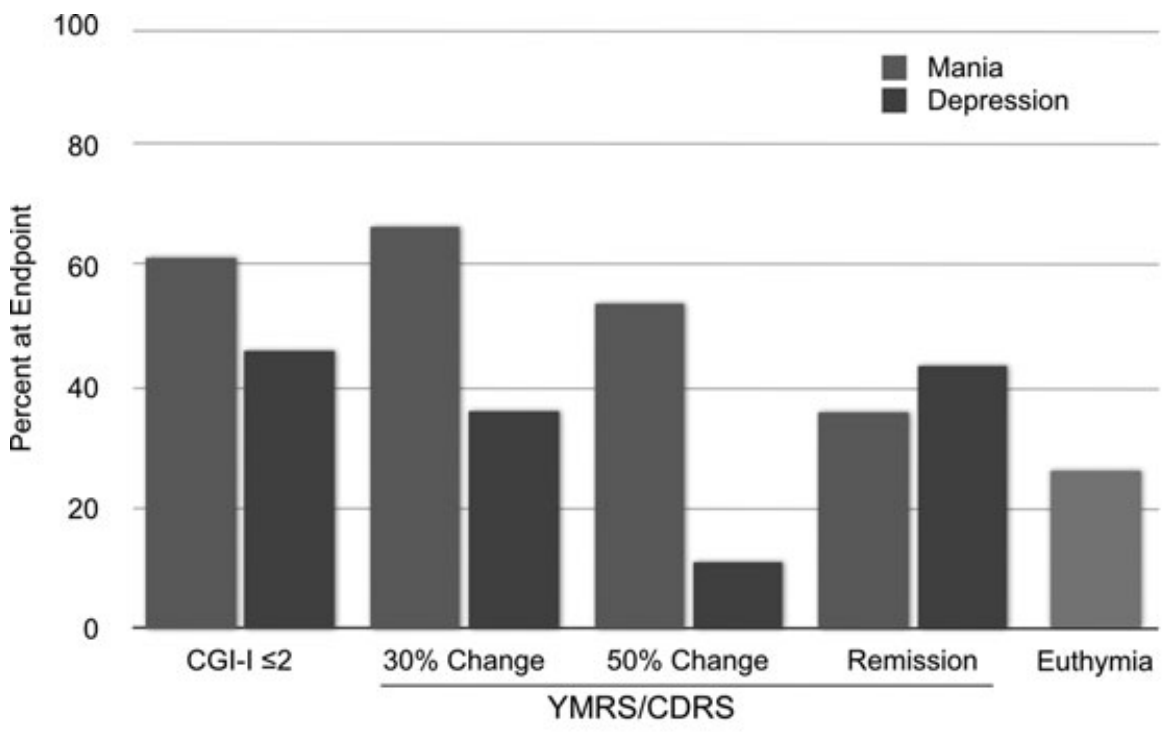

CGI-I: CGI-Improvement scale scored for Mania and Depression separately. Mania was assessed with the YMRS and depression with the CDRS. $30 \%$ and $50 \%$ change refer to changes in these ratings relative to baseline. Remission from mania or depression was defined at YMRS $<12$ or CDRS $<28$, respectively. Euthymia was defined as a YMRS $<12$ and a CDRS $<28$.

Figure 2 Rate of response of mania and depression in 39 subjects openly treated with lamotrigine. CGI-I: CGI-Improvement scale scored for mania and depression separately. Mania was assessed with the YMRS and depression with the CDRS. 30\% and 50\% change refer to changes in these ratings relative to baseline. Remission from mania or depression was defined at YMRS $<12$ or CDRS $<28$, respectively. Euthymia was defined as a YMRS $<12$ and a CDRS $<28$. were (not mutually exclusive): dermatological $(\mathrm{N}=7)$, GI complaints $(\mathrm{N}=2)$, musculoskeletal $(\mathrm{N}=1)$, headache $(\mathrm{N}=3)$, and cold symptoms $(\mathrm{N}=1)$.

In all 15/39 subjects developed skin lesions at any point during the trial; 13/15 skin lesions were skin rashes and the remaining lesions were single cases of topical burn and chapped lips(Table 2). Six subjects developed mild rash of known etiology (contact dermatitis [ $\mathrm{N}=2]$, sunburn $[\mathrm{N}=2]$, and dry skin $[\mathrm{N}=2]$ ), which resolved within a week of identification and these subjects successfully completed the trial. The remaining $7 / 13$ subjects developed rash of unknown etiology; one developed mild petechiae in the abdominal region which resolved within a week without discontinuing the trial, and the remaining six discontinued the trial due to rash. Five of seven subjects with rash of unknown etiology developed rash within 6 weeks of exposure to lamotrigine $\leq 50 \mathrm{mg} /$ day. All subjects that discontinued the trial developed maculopapular rash $(5 / 6)$ with the exception of one subject who developed multiple, pruritic, vescicular rash on the right side of the face. Maculo-papular rashes were multiple (in one case solitary), on the limbs (in two cases also on the trunk), pruritic (with the exception of one case), nonprogressive (except for one case) with mild-moderate severity and resolved within 1 week of discontinuation of lamotrigine. Among the subjects that discontinued the trial due to rash of unknown etiology, one subject was also receiving cephalexin for sore throat, an antibiotic with known adverse effect of skin rash, and in another case there was history of family member simultaneously developing similar rash. Notably, none of the participants in the trial developed serious rash (life-threatening or requiring hospitalization, Stevens Johnson syndrome, or erythema multiforme) or developed mucosal rash in conjunction with the skin rash.

\section{Discussion}

This was a prospective, 12-week, open-label treatment trial of lamotrigine monotherapy in 39 youth with bipolar I, II, or bipolar not otherwise specified. Subjects participating in this study were young $(10.8 \pm 2.9$ years $)$ predominantly males $(61 \%, \mathrm{~N}=24)$ with bipolar I disorder experiencing significant symptoms of mania (YMRS $31.6 \pm 5.5)$. Intent to treat analysis showed that subjects improved significantly from baseline to endpoint in symptoms of mania, depression, psychosis, and ADHD as measured by syndrome-specific rating scales and clinical global impression. Treatment with lamotrigine was generally tolerable with minimal impact on weight and metabolic parameters, but $25 \%$ of subjects discontinued the trial due to adverse effects. Although no participant 
Table 1 Baseline and endpoint metabolic results

\begin{tabular}{|c|c|c|c|c|}
\hline & Baseline & Endpoint & $F(1,38)$ & $P$-value \\
\hline Pulse & $85.8 \pm 14.6$ & $82.3 \pm 11.7$ & 1.3 & 0.3 \\
\hline Systolic blood pressure (mmHg) & $108.5 \pm 11.6$ & $108.6 \pm 10.9$ & $<0.01$ & 0.9 \\
\hline Diastolic blood pressure (mmHg) & $62.4 \pm 11.3$ & $61.6 \pm 11.4$ & 0.1 & 0.7 \\
\hline PR interval & $135.1 \pm 17.4$ & $138.1 \pm 20.1$ & 1.6 & 0.2 \\
\hline QRS interval & $82.9 \pm 7.8$ & $82.4 \pm 7.1$ & 0.2 & 0.6 \\
\hline QTc interval & $410.0 \pm 12.6$ & $403.9 \pm 12.2$ & 6.9 & 0.01 \\
\hline Sodium level & $139.5 \pm 1.5$ & $140.4 \pm 1.5$ & 5.1 & 0.03 \\
\hline Potassium level & 4.0. \pm 0.3 & $4.1 \pm 0.5$ & 1.4 & 0.2 \\
\hline Chlorine level & $103.3 \pm 1.4$ & $103.1 \pm 1.8$ & 0.2 & 0.7 \\
\hline Carbon dioxide level (mm/L) & $26.2 \pm 2.3$ & $26.6 \pm 2.4$ & 1.1 & 0.3 \\
\hline Calcium level (mg/dL) & $9.7 \pm 0.3$ & $9.7 \pm 0.4$ & 0.4 & 0.5 \\
\hline Urea nitrogen level & $13.7 \pm 3.0$ & $12.7 \pm 3.4$ & 3.2 & 0.08 \\
\hline Creatinine level & $0.72 \pm 0.14$ & $0.78 \pm 0.18$ & 9.1 & 0.005 \\
\hline Glucose level & $84.8 \pm 12.9$ & $85.2 \pm 10.4$ & 0.02 & 0.9 \\
\hline SGPT (ALT) & $19.2 \pm 8.6$ & $20.3 \pm 12.3$ & 0.4 & 0.5 \\
\hline SGOT (AST) & $27.1 \pm 6.4$ & $28.4 \pm 8.1$ & 1.7 & 0.2 \\
\hline WBC & $7.6 \pm 1.8$ & $7.6 \pm 2.2$ & 0.01 & 0.9 \\
\hline $\mathrm{HCT}$ & $38.5 \pm 2.8$ & $39.1 \pm 2.9$ & 2.2 & 0.1 \\
\hline$H G B$ & $13.5 \pm 1.1$ & $13.7 \pm 1.2$ & 1.0 & 0.3 \\
\hline $\mathrm{RBC}$ & $4.7 \pm 0.4$ & $4.8 \pm 0.3$ & 1.1 & 0.3 \\
\hline PLT & $316.8 \pm 55.5$ & $339.9 \pm 68.9$ & 5.5 & 0.03 \\
\hline MCV & $82.1 \pm 5.7$ & $82.6 \pm 5.9$ & 0.9 & 0.4 \\
\hline $\mathrm{MCH}$ & $28.8 \pm 2.3$ & $28.8 \pm 2.3$ & 0.01 & 0.9 \\
\hline $\mathrm{MCHC}$ & $35.0 \pm 1.3$ & $34.8 \pm 1.1$ & 0.9 & 0.4 \\
\hline RDW & $13.2 \pm 0.8$ & $13.3 \pm 0.9$ & 0.1 & 0.7 \\
\hline
\end{tabular}

SGPT (ALT) indicates alanine transaminase; SGOT (AST), aspartame transaminase; WBC, white blood cell count; HCT, hematocrit; HGB, hemoglobin; RBC, red blood cell count; PLT, platelet count; MCV, mean corpuscular volume; $\mathrm{MCH}$, mean corpuscular hemoglobin; MCHC, mean corpuscular hemoglobin concentration; RDW, red blood cell distribution width.

developed Steven Johnson syndrome, dermatological adverse effects were common. These results suggest that lamotrigine monotherapy may be beneficial and well tolerated in the management of both mania and depression in children with BPD.

Our positive mood stabilizing effects associated with lamotrigine monotherapy are consistent with the only previous prospective open-label study of lamotrigine in the treatment of pediatric bipolar disorder by Chang et al. [32]. This was an 8-week open-label trial of lamotrigine (mean final dose was $131.6 \mathrm{mg} /$ day) in 20 adolescents ( $\mathrm{n}=19$ completers) with diagnoses of bipolar disorder I, II, or not otherwise specified $(30 \%$ of subjects were taking other psychotropic medications). At week 8 , $84 \%$ responded and $58 \%$ were considered in remission. YMRS and Overt Aggression Scale-Modified scores also decreased significantly during the trial. There was no significant weight change, rash, or other adverse effects during the trial.

Our findings documenting significant antimanic effects associated with open-label treatment with lamotrigine are consistent with results observed in open-label studies of divalproex sodium. Kowatch et al. reported [33] response rates of $53 \%$ for divalproex sodium in a 6-week open label study and Pavaluri et al. (2005) reported significant antimanic effects associated with treatment with divalproex sodium in a 6-month open-label study of divalproex sodium in pediatric bipolar disorder [34]. However, although an open-label study of divalproex sodium in pediatric bipolar disorder by Wagner et al. reported improvement in manic symptoms in its open-label phase, very few subjects improved sufficiently to be eligible to enter a planned double-blind discontinuation study following the open-label treatment [35]. Likewise, while a 6-month open-label study of divalproex sodium extended release in the treatment of children and adolescents with acute mania by Redden et al. (226 subjects enrolled; 109 completed) reported improvement in manic symptoms, small improvements were seen in behavior and caregiver stress ratings and weight gain (16\%), nausea $(9 \%)$, increased appetite $(8 \%)$, and elevations of mean ammonia levels in plasma were common [36]. In contrast, a 


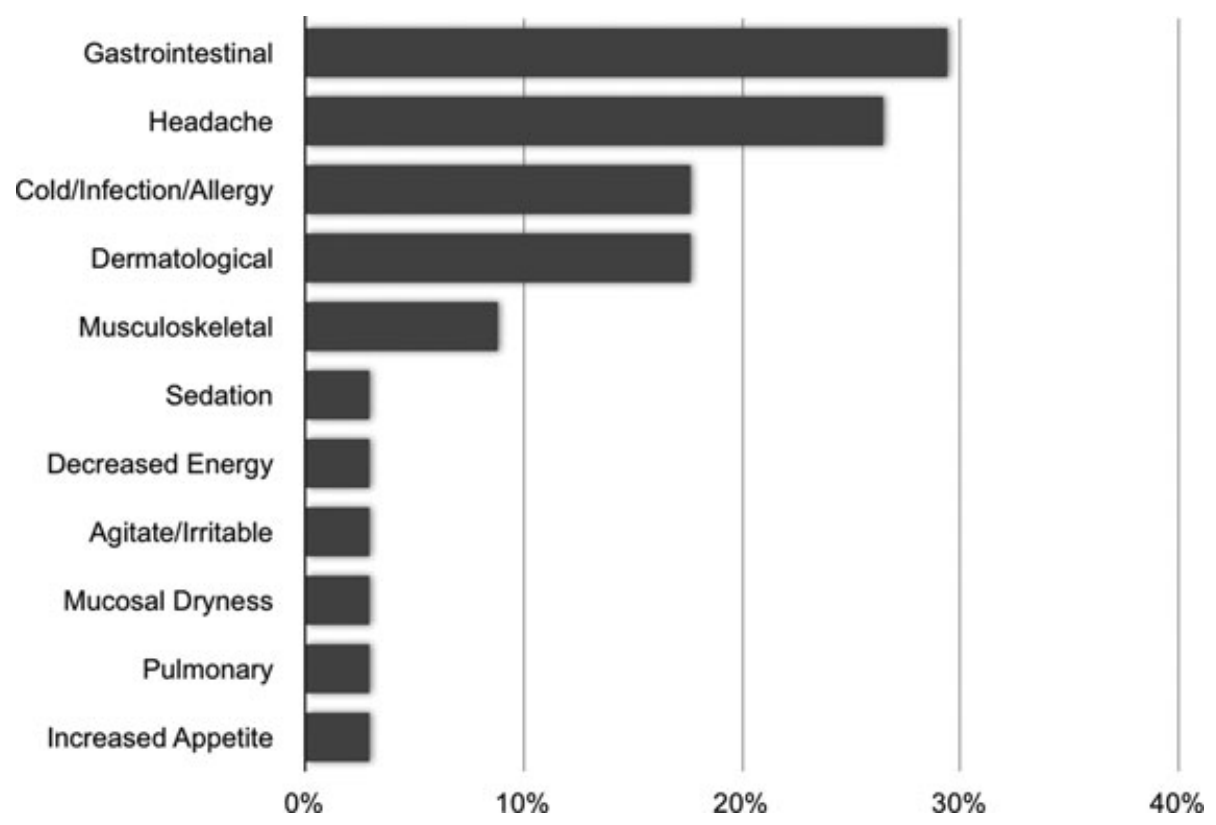

Figure 3 Adverse effects reported in 39 subjects openly treated with lamotrigine over 12 weeks.

recently completed randomized clinical trial of divalproex sodium extended release in the treatment of children and adolescents with bipolar disorder failed to show separation from placebo [37]. Very modest effects also observed in open-label studies of carbamazepine immediate (CBZ-IR) [38] and extended (CBZ-ER) release formulations [39] and in a controlled clinical trial oxcarbazepine failed to show separation from placebo [40].

The observed antidepressant effects associated with lamotrigine treatment in the present pediatric trial is consistent with the substantial evidence available from previous controlled trials in adults indicating that lamotrigine may be efficacious in improving the depressive symptoms of mixed episodes in adult populations with BPD $[41,42]$. They are also consistent with findings reported by Chang et al. [43] documenting clinical and significant decreases in ratings of depression in eight adolescents with bipolar disorder following 8 weeks of treatment with lamotrigine that were correlated with amygdalar activation using f-MRI [43]. They are also consistent with retrospective findings reported by Soutullo et al. [44] in a small sample of Spanish adolescents with bipolar spectrum depression. Considering the manicogenic potential of antidepressants in the management of bipolar youth, if confirmed in larger controlled trials, these findings would support the use of lamotrigine in the management of both the manic, depressed, and the mixed manic states [45] that characterize juvenile bipolar disorder [46].
Equally noteworthy is the observation that treatment with lamotrigine was associated with improvement across other domains of comorbid psychopathology measured by the BPRS and the ADHD rating scale. Considering that psychotic features are commonly associated with pediatric bipolar disorder, if confirmed in larger randomized clinical trials, this finding would suggest that treatment with lamotrigine monotherapy could be adequate in the management of bipolar youth with and without comorbid psychosis. Likewise, considering the very high rates of ADHD comorbidity in pediatric bipolar disorder $[47,48]$ and the potential manicogenic effect of stimulant drugs [49-51], if confirmed in larger randomized clinical trials, this finding would suggest that lamotrigine monotherapy could help manage both the bipolar as well as the ADHD symptomatology in some youth with bipolar disorder. More work is needed to determine if the improvement in these comorbid domains is attributable to the lamotrigine specifically or if the symptomatic improvement is secondary to mood stabilization.

For the majority of subjects in our study, treatment with lamotrigine was well tolerated at the mean dose of $160.7 \pm 128.3$ in subjects $<12$ years of age $(\mathrm{N}=22)$ and $219.1 \pm 172.2 \mathrm{mg} /$ day in adolescents. There were no serious adverse effects. Of the 39 subjects enrolled, $22(56 \%)$ completed the 12 -week course. Of those that dropped out, 10 did so due to adverse effects. In general, most adverse effects were considered mild or moderate. Cardiovascular parameters including blood pressure, 
Table 2 Dermatological adverse effects reported

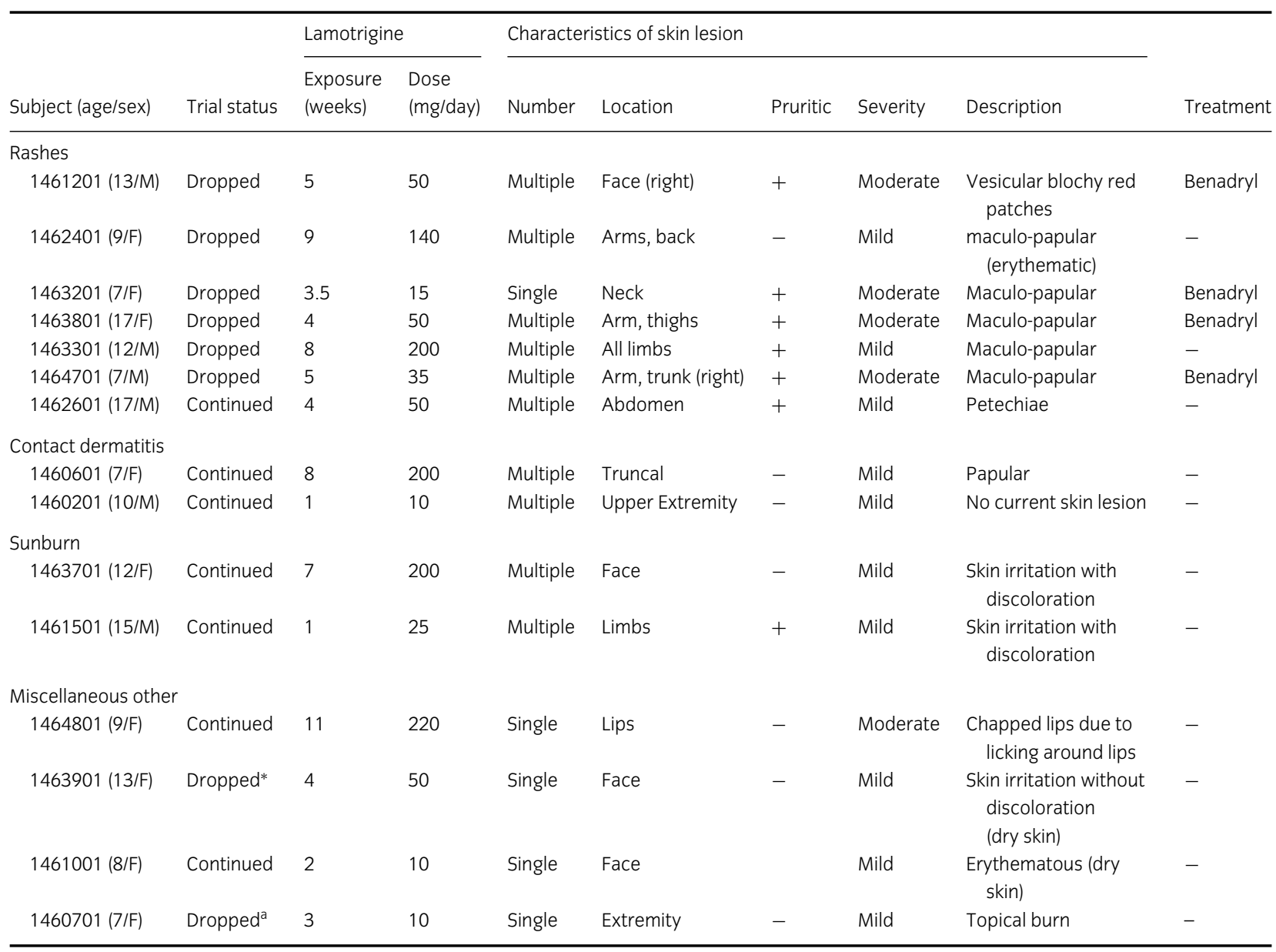

${ }^{a}$ Dropped due to other reasons than rash; +, present; -, absent/none.

heart rate, and ECG values following treatment with lamotrigine were within normal limits. Mean values of all safety laboratory tests including glucose and lipid parameters remained within normal limits throughout the trial. It is particularly noteworthy that in this acute treatment with lamotrigine, weight gain was minimal.

Although skin rashes were relatively common, none of the participants in the trial developed a serious rash (lifethreatening, requiring hospitalization, Stevens Johnson syndrome or erythema multiforme). In all, 39\% (15/39) of the youth developed skin lesion at some point during the trial. Of these, six discontinued the trial due to the rash. With the exception of one of these six subjects who developed multiple, pruritic, vescicular rash on the right side of the face, the other five subjects developed a nonprogressive maculo-papular rash. The rash developed within 6 weeks of exposure to lamotrigine at doses of $\leq 50 \mathrm{mg} /$ day in $67 \%(4 / 6)$ of the youth that discontinued lamotrigine trial due to rash. In all cases, the rash resolved promptly (within a week) after discontinuation of lamotrigine.

The results of this study need to be considered in light of some methodological limitations. This was an open study; therefore, the assessments were not blind to treatment. We also did not employ a placebo-control group and, therefore, cannot separate the effects of treatment from time. We also included subjects with bipolar spectrum disorders not with a sample size needed to stratify subjects based upon diagnostic category. Concomitant pharmacotherapy (with the exception of mood stabilizers, anticonvulsants, neuroleptics, and antidepressants) or psychotherapy were allowed during the study if these treatments were in place at baseline and were not modified during the 12-week open-label trial. There were insufficient number of subjects receiving any particular pharmacotherapy to estimate the impact of concomitant treatment on the clinical response presented here; we did not systematically collect information regarding 
concomitant psychotherapy. Although reports of adverse effects were common in our data, our assessment of adverse effects relied exclusively on spontaneous reports by subjects and their parents.

Despite these considerations, this open-label trial of lamotrigine monotherapy showed that acute treatment with lamotrigine was associated with antimanic, antidepressant, antipsychotic, and anti-ADHD responses in children and adolescents with bipolar and bipolar spectrum disorder. In this short-term trial, treatment with lamotrigine monotherapy was relatively well tolerated. Although no child developed Steven Johnson syndrome, skin rashes were relatively common despite the slow titration rate. Despite these encouraging results, firmer conclusions regarding the safety and efficacy of lamotrigine in the treatment of pediatric bipolar disorder await results from larger and controlled clinical trials.

\section{Acknowledgment}

Funding source: This work is supported by the Kimmerly-Neal Fund for the Study of Cognition and Psychiatric Disorders in Children and the Pediatric Psychopharmacology Council Fund.

\section{Disclosures}

Dr. Joseph Biederman is currently receiving research support from the following sources: Alza, AstraZeneca, Bristol Myers Squibb, Eli Lilly and Co., Janssen Pharmaceuticals Inc., McNeil, Merck, Organon, Otsuka, Shire, NIMH, and NICHD.

\section{Conflict of Interest}

Dr. Joseph Biederman is currently receiving research support from the following sources: Alza, AstraZeneca, Bristol Myers Squibb, Eli Lilly and Co., Janssen Pharmaceuticals Inc., McNeil, Merck, Organon, Otsuka, Shire, NIMH, and NICHD. In 2009, Dr. Joseph Biederman received a speaker's fee from the following sources: Fundacion Areces, Medice. In previous years, Dr. Joseph Biederman received research support, consultation fees, or speaker's fees for/from the following additional sources: Abbott, AstraZeneca, Celltech, Cephalon, Eli Lilly and Co., Esai, Forest, Glaxo, Gliatech, Janssen, McNeil, NARSAD, NIDA, New River, Novartis, Noven, Neurosearch, Pfizer, Pharmacia, The Prechter Foundation, Shire, The Stanley Foundation, UCB Pharma, Inc. and Wyeth.

Dr. Gagan Joshi discloses the following potential conflicts of interest: Ethel DuPont Warren Fellowship Award 2005-6, a Pilot Research Award from the American Academy of Child and Adolescent Psychiatry 2005,
McNeil Pediatrics (CME sponsored by SynerMed Communications), Bristol Myers Squibb (Site PI for Multicentered Trial), Glaxo Smith Kline (Site PI for Multicentered Trial), and Shire (Member of national advisory board). Dr. Gagan Joshi is a subinvestigator for clinical trials sponsored by Shire, Johnson \& Johnson, Pfizer, Merck, Cephlon, McNeil, Eli-Lily, Abbott, Novartis, Bristol Myers Squibb, Organon, Otsuka, Takeda, and New River Pharmaceuticals.

Dr. Eric Mick receives research support from the following sources and is on an advisory board for the following sources: McNeil Pediatrics, Ortho-McNeil Janssen Scientific Affairs, Pfizer, Shire Pharmaceuticals, and the National Institute of Mental Health (NIMH) and has had an advisory or consulting relationship with Pfizer and Shire Pharmaceutical.

Dr. Robert Doyle discloses the following potential conflicts of interest: Shire, Lilly, Novartis, McNeil, Janssen, Bristol Myers Squibb, Elan, Celltech, NEI, Phase V, CME Outfitters, PriMed, Effikacy, Danemiller Foundation.

Dr. Georgiopoulos received an unrestricted educational grant for a 2005 book from GlaxoSmithKline. She received an honorarium for a Continuing Medical Education presentation from Pri-Med/Physicians Academy for Clinical and Management Excellence, supported by an educational grant from McNeil Pediatrics, administered by Ortho-McNeil Janssen Scientific Affairs. She has participated as Sub-Investigator or Co-Investigator on research studies funded by the following: Bristol Myers Squibb Research Institute, Cephalon, Eli-Lilly $\&$ Co., GlaxoSmithKline, McNeil Consumer and Specialty Pharmaceuticals, Novartis Pharmaceuticals Corporation, Shire Development/Shire Pharmaceuticals; as well as NIH-NIMH, NIH-NIDA, NARSAD, the Stanley Foundation, and Harvard Medical School/Massachusetts General Hospital.

Dr. Hammerness has been a speaker for, received research funds or participated in CME activities/ professional talks supported by the following pharmaceutical companies: Abbott, Eli Lilly \& Company, Forest Research Institute, Ortho-McNeil-Janssen, and Shire. Dr. Hammerness has also received research funds from Elminda Ltd. Dr. Hammerness has also participated, as an investigator, in research studies in the past 2 years funded by the following pharmaceutical companies: Bristol Myers Squibb, Cephalon, Eli Lilly, GlaxoSmithKline, Johnson \& Johnson, McNeil, New River, Novartis, Organon, Otsuka, Pfizer, Shire, Takeda. Dr. Hammerness has also received honoraria from Reed Medical Education (a company working as a logistics collaborator for the MGH Psychiatry Academy). The education programs conducted by the MGH Psychiatry Academy are supported through Independent Medical Education (IME) grants 
from pharmaceutical companies co-supporting programs along with participant tuition. Commercial entities supporting the MGH Psychiatry Academy are listed on the Academy's website, www.mghcme.org.

Meghan Kotarski, MBA, has no conflict of interest to disclose.

Courtney Willams, BA, has no conflict of interest to disclose.

Janet Wozniak, MD, is the Author of "Is Your Child Bipolar" published May 2008, Bantam Books. Dr. Wozniak is a speaker for McNeil, Primedia/MGH Psychiatry Academy, and is on the Speakers Bureau for Lilly. Dr. Wozniak is on the Advisory Board/Consulting for Pfizer and Shire. Dr. Wozniak receives research support for McNeil, Shire, and Lilly. Dr. Wozniak's spouse, John Winkelman, MD, $\mathrm{PhD}$, is on the Speakers Bureau for Boehringer-Ingelheim, Cephalon, GlaxoSmithKline, King, Sanofi-Aventis, Sepracor, and Takeda, is on the Advisory Board/Consulting for Axon Labs, Boehringer-Ingelheim, GlaxoSmithKline, Jazz Pharmaceuticals, Novartis, Neurogen, Novadel Pharma, Pfizer, UCB (Schwarz) Pharma, Sanofi-Aventis, Sepracor, and Takeda, and receives research support from BoehringerIngelheim, GlaxoSmithKline, UCB (Schwarz) Pharma, Pizer, and Sepracor.

The Kimmerly-Neal Fund for the Study of Cognition and Psychiatric Disorders in Children and the Pediatric Psychopharmacology Council Fund.

\section{References}

1. Wozniak J. Pediatric bipolar disorder: The new perspective on severe mood dysfunction in children. $J$ Child Adolesc Psychopharmacol 2003;13:449-451.

2. Geller B, Fox L, Clark K. Rate and predictors of prepubertal bipolarity during follow-up 6- to 12-year-old depressed children. J Am Acad Child Adolesc Psychiatry 1994;33:461-468.

3. Lewinsohn P, Klein D, Seeley J. Bipolar disorders in a community sample of older adolescents: Prevalence, phenomenology, comorbidity, and course. J Am Acad Child Adolesc Psychiatry 1995;34:454-463.

4. Biederman J, Mick E, Faraone SV, Spencer T, Wilens TE, Wozniak J. Pediatric mania: A developmental subtype of bipolar disorder? Biol Psychiatry 2000;48:458-466.

5. Biederman J, Mick E, Bostic J, et al. The naturalistic course of pharmacologic treatment of children with manic-like symptoms: A systematic chart review. J Clin Psychiatry 1998;59:628-637; quiz 38.

6. Tohen M, Ketter TA, Zarate CA, et al. Olanzapine versus divalproex sodium for the treatment of acute mania and maintenance of remission: A 47-week study. Am J Psychiatry 2003;160:1263-1271.
7. Keck PE Jr, Versiani M, Potkin S, West SA, Giller E, Ice $\mathrm{K}$. Ziprasidone in the treatment of acute bipolar mania: A three-week, placebo-controlled, double-blind, randomized trial. Am J Psychiatry 2003;160: 741-748.

8. Perlis RH, Welge JA, Vornik LA, Hirschfeld RM, Keck PE Jr. Atypical antipsychotics in the treatment of mania: A meta-analysis of randomized, placebo-controlled trials. $J$ Clin Psychiatry 2006;67:509-516.

9. Frazier JA, Biederman J, Tohen M, et al. A prospective open-label treatment trial of olanzapine monotherapy in children and adolescents with bipolar disorder. $J$ Child Adolesc Psychopharmacol 2001;11:239-250.

10. Biederman J, Mick E, Wozniak J, Aleardi M, Spencer T, Faraone SV. An open-label trial of risperidone in children and adolescents with bipolar disorder. $J$ Child Adolesc Psychopharmacol 2005;15:311-317.

11. Biederman J, Mick E, Hammerness P, et al. Open-label, 8 -week trial of olanzapine and risperidone for the treatment of bipolar disorder in preschool-aged children. Biol Psychiatry 2005;58:589-594.

12. DelBello MP, Kowatch RA, Adler CM, et al. A double-blind randomized pilot study comparing quetiapine and divalproex for adolescent mania. $J$ Am Acad Child Adolesc Psychiatry 2006;45:305-313.

13. Bowden C, Calabrese J, McElroy S, et al. The efficacy of Lamotrigine in rapid cycling and non-rapid cycling patients with bipolar disorder. Biol Psychiatry 1999; 45:953-958.

14. Bowden CL, Asnis GM, Ginsberg LD, Bentley B, Leadbetter R, White R. Safety and tolerability of lamotrigine for bipolar disorder. Drug Safety 2004; 27:173-184.

15. Fatemi SH, Rapport DJ, Calabrese JR, Thuras P. Lamotrigine in rapid-cycling bipolar disorder. $J$ Clin Psychiatry 1997; 58:522-527.

16. Passmore MJ, Garnham J, Duffy A, et al. Phenotypic spectra of bipolar disorder in responders to lithium versus lamotrigine. Bipolar Disord 2003;5:110-114.

17. Obrocea GV, Dunn RM, Frye MA, et al. Clinical predictors of response to lamotrigine and gabapentin monotherapy in refractory affective disorders. Biol Psychiatry 2002; 51:253-260.

18. Marangell LB, Martinez JM, Ketter TA, et al. Lamotrigine treatment of bipolar disorder: Data from the first 500 patients in STEP-BD. Bipolar Disord 2004;6:139-143.

19. Calabrese JR, Suppes T, Bowden CL, et al. A double-blind, placebo-controlled, prophylaxis study of lamotrigine in rapid-cycling bipolar disorder. Lamictal 614 Study Group. J Clin Psychiatry 2000; 61:841-850.

20. Sporn J, Sachs G. The anticonvulsant lamotrigine in treatment-resistant manic-depressive illness. J Clin Psychopharmacol 1997; 17:185-189. 
21. Yatham LN, Kusumakar V, Parikh SV, et al. Bipolar depression: Treatment options. Can J Psychiatry 1997;42(Suppl 2):87S-91S.

22. Ichim L, Berk M, Brook S. Lamotrigine compared with lithium in mania: A double-blind randomized controlled trial. Ann Clin Psychiatry 2000;12:5-10.

23. Calabrese JR, Sullivan JR, Bowden CL, et al. Rash in multicenter trials of lamotrigine in mood disorders: Clinical relevance and management. J Clin Psychiatry 2002;63:1012-1019.

24. Orvaschel H, Puig-Antich J. Schedule for Affective Disorders and Schizophrenia for School-Age Children: Epidemiologic Version. Fort Lauderdale, FL: Nova University, 1987.

25. Fristad MA, Weller RA, Weller EB. The Mania Rating Scale (MRS): Further reliability and validity studies with children. Ann Clin Psychiatry 1995;7:127-132.

26. Fristad MA, Weller EB, Weller RA. The Mania Rating Scale: Can it be used in children? A preliminary report. J Am Acad Child Adolesc Psychiatry 1992;31:252-257.

27. Young R, Biggs J, Ziegler V, Meyer D. A rating scale for mania: Reliability, validity and sensitvity. Br J Psychiatry 1978;133:429-435.

28. Youngstrom EA, Danielson CK, Findling RL, Gracious BL, Calabrese JR. Factor structure of the Young Mania Rating Scale for use with youths ages 5 to 17 years. $J$ Clin Child Adolesc Psychol 2002;31:567-572.

29. Poznanski EO, Cook SC, Carroll BJ. A depression rating scale for children. Pediatrics 1979;64:442-450.

30. Lachar D, Bailley SE, Rhoades HM, et al. New subscales for an anchored version of the brief psychiatric rating scale: Construction, reliability, and validity in acute psychiatric admissions. Psychol Assess 2001;13: 384-395.

31. National Institute of Mental Health. CGI (Clinical Global Impression) Scale-NIMH. Psychopharmacol Bull 1985; 21:839-844.

32. Chang K, Saxena K, Howe M. An open-label study of lamotrigine adjunct or monotherapy for the treatment of adolescents with bipolar depression. J Am Acad Child Adolesc Psychiatry 2006;45:298-304.

33. Kowatch RA, Suppes T, Carmody TJ, et al. Effect size of lithium, divalproex sodium, and carbamazepine in children and adolescents with bipolar disorder. $J$ Am Acad Child Adolesc Psychiatry 2000;39:713-720.

34. Pavuluri MN, Henry DB, Carbray JA, Naylor MW, Janicak PG. Divalproex sodium for pediatric mixed mania: A 6-month prospective trial. Bipolar Disord 2005;7: 266-273.

35. Wagner KD, Weller E, Carlson GA, et al. An open-label trial of divalproex in children and adolescents with bipolar disorder. J Am Acad Child Adolesc Psychiatry 2002;41:1224-1230.

36. Redden L, DelBello M, Wagner KD, et al. Long-term safety of divalproex sodium extended-release in children and adolescents with bipolar I disorder. $J$ Child Adolesc Psychopharmacol 2009;19:83-89.

37. Wagner KD, Redden L, Kowatch RA, et al. A double-blind, randomized, placebo-controlled trial of divalproex extended-release in the treatment of bipolar disorder in children and adolescents. J Am Acad Child Adolesc Psychiatry 2009;48:519-532.

38. Weisler RH, Hirschfeld R, Cutler AJ, et al. Extended-release carbamazepine capsules as monotherapy in bipolar disorder: Pooled results from two randomised, double-blind, placebo-controlled trials. CNS Drugs 2006;20:219-231.

39. Joshi G, Wozniak J, Mick E, et al. A prospective open-label trial of extended release carbamazepine (Equetro ${ }^{\circledR}$ ) monotherapy in children with bipolar disorder. J Child Adolesc Psychopharmacol 2009; in press.

40. Wagner KD, Kowatch RA, Emslie GJ, et al. A double-blind, randomized, placebo-controlled trial of oxcarbazepine in the treatment of bipolar disorder in children and adolescents. Am J Psychiatry 2006;

163:1179-1186.

41. Calabrese J, Bowden C, Sachs G, Ascher J, Monaghan E, Rudd D. A double-blind placebo-controlled study of lamotrigine, monotherapy in outpatients with bipolar I depression. J Clin Psychiatry 1999;60:79-88.

42. Goodwin GM, Bowden CL, Calabrese JR, et al. A pooled analysis of 2 placebo-controlled 18-month trials of lamotrigine and lithium maintenance in bipolar I disorder. J Clin Psychiatry 2004;65:432-441.

43. Chang KD, Wagner C, Garrett A, Howe M, Reiss A. A preliminary functional magnetic resonance imaging study of prefrontal-amygdalar activation changes in adolescents with bipolar depression treated with lamotrigine. Bipolar Disord 2008;10:426-431.

44. Soutullo CA, Diez-Suarez A, Figueroa-Quintana A. Adjunctive lamotrigine treatment for adolescents with bipolar disorder: Retrospective report of five cases. J Child Adolesc Psychopharmacol 2006;16:357-364.

45. Tohen M, Zarate CA Jr., Centorrino F, Hegarty JI, Froeschl M, Zarate SB. Risperidone in the treatment of mania. J Clin Psychiatry 1996;57:249-253.

46. Wozniak J, Biederman J, Kiely K, et al. Mania-like symptoms suggestive of childhood onset bipolar disorder in clinically referred children. J Am Acad Child Adolesc Psychiatry 1995;34:867-876.

47. Wozniak J, Biederman J, Faraone S, et al. Mania in children with pervasive developmental disorder revisited. J Am Acad Child Adolesc Psychiatry 1997;36:1552-1560.

48. Biederman J, Faraone SV, Mick E, et al. Attention deficit hyperactivity disorder and juvenile mania: An overlooked comorbidity? J Am Acad Child Adolesc Psychiatry 1996; 35:997-1008.

49. Koehler-Troy C, Strober M, Malenbaum R. Methylphenidate-induced mania in a prepubertal child. J Clin Psychiatry 1986;47:566-567. 
50. Schmidt K, Delaney MA, Jensen M, Levinson DF, Lewitt M. Methylphenidate challenge in a manic boy. Biol Psychiatry 1986;21:1107-1109.

51. Soutullo CA, DelBello MP, Ochsner JE, McElroy SL,
Taylor SA, Strakowski SM, Keck PE Jr. Severity of bipolarity in hospitalized manic adolescents with history of stimulant or antidepressant treatment. $J$ Affect Disord 2002;70:323-327. 